\title{
The impact of physical activity during pregnancy on maternal weight and obstetric outcomes
}

\author{
Małgorzata Mizgier ${ }^{1}$, Kinga Mruczyk ${ }^{1}$, Grażyna Jarząbek-Bielecka², Jan Jeszka ${ }^{3}$ \\ ${ }^{1}$ Poznan University of Physical Education, Department of Morphological and Health Sciences, Dietetic Division, \\ Faculty of Physical Culture in Gorzow Wielkopolski, Poland \\ ${ }^{2}$ Division of Gynecology, Department of Perinatology and Gynecology, Poznan University of Medical Science, Poland \\ ${ }^{3}$ Department of Hygiene and Human Nutrition, Diabetic Division, Poznan University of Life Sciences, Poland
}

\begin{abstract}
Objectives: The goal of the paper was to compare weight gain in pregnant women in relation to the week of gestation at birth, the delivery method, and the occurrence of macrosomia and low birth weights for patients with different durations of physical activity during pregnancy.

Material and methods: The full course of study was completed by 57 pregnant women enrolled in an 18-week physical activity programme during their second and third trimesters. The actual duration of their physical activity was monitored with the ActiGraph GT3X monitor. The patients were divided into two groups: L_MPA $(n=28)$ - pregnant women with daily physical activity of over 21.38 minutes and S_MPA $(n=29)$ - pregnant women who exercised less than 21.38 minutes a day. The study compared obstetric results in both groups.

Results: Significantly more patients in the S_MPA group exhibited excess weight gain as compared with the L_MPA group ( $p=0.01$ ). There was found to be no significant impact from the duration of physical activity on the occurrence of macrosomia or low birth weight, the gestation age at birth or the delivery method. However, there were two times fewer cases of macrosomia in the L_MPA group.

Conclusions: The results demonstrate that physical activity during pregnancy for at least 21 minutes per day in the second half of the pregnancy reduces the risk of excess weight gain during pregnancy.
\end{abstract}

Key words: physical activity, pregnancy, pregnancy outcomes, excessive weight gain

Ginekologia Polska 2018; 89, 2: 80-88

\section{INTRODUCTION}

An appropriate lifestyle (with moderate physical activity, proper diet and so on) among reproductive age women affects the mother's health and reduces the risk of complications related to fetal development and the occurrence of chronic diseases in children later in life. Optimum weight gain, proper physical activity and a varied diet are the key characteristics of a healthy lifestyle during pregnancy [1, 2].

In 1990, the Institute of Medicine of the National Academy of Science (IOM) drafted recommendations on the optimal weight gain during pregnancy dependent on the woman's body mass index (BMI) before pregnancy. According to these recommendations, weight gain in women with a BMI below $19.8 \mathrm{~kg} / \mathrm{m}^{2}$ should be between 12.5 and $18 \mathrm{~kg}$ and for those with a BMI of 19.8 to $26 \mathrm{~kg} / \mathrm{m}^{2}$, between $11.5 \mathrm{~kg}$ and $16 \mathrm{~kg}$. The smallest weight gain was recommended for overweight and obese women. For a BMI ranging from 26.1 to $29.0 \mathrm{~kg} / \mathrm{m}^{2}$, the recommended weight gain is between $7 \mathrm{~kg}$ and $11.5 \mathrm{~kg}$; while for a BMI over $29 \mathrm{~kg} / \mathrm{m}^{2}$, it is less than $7 \mathrm{~kg}$. These recommendations were modified in 2009. The new IOM recommendations specify a weight gain of between $12.5 \mathrm{~kg}$ and $18 \mathrm{~kg}$ for a BMI below $18.5 \mathrm{~kg} / \mathrm{m}^{2}$; between $11.5 \mathrm{~kg}$ and $16 \mathrm{~kg}$ for a BMI between 18.5 and $24.9 \mathrm{~kg} / \mathrm{m}^{2}$; a weight gain of between $10 \mathrm{~kg}$ and $11.5 \mathrm{~kg}$ for a BMI between 25.0 and $29.9 \mathrm{~kg} / \mathrm{m}^{2}$; and a weight gain of less than 5 to $9 \mathrm{~kg}$ for a BMI over $30.0 \mathrm{~kg} / \mathrm{m}^{2}$ [3].

Women with the recommended weight gain exhibit a lower risk of complications during pregnancy and delivery $[4,5]$. 
Excess weight gain is detrimental to obstetric results and increases the risk of complications both in the mother and the fetus [6-8]. Obese women exhibit a higher risk of pregnancy-induced hypertension and gestational diabetes, among other risks [2].

In mothers with excess weight gain in relation to the IOM recommendations, neonates are more often scored lower on the APGAR'5 scale; and more often suffer from hypoglycaemia, polycythaemia, meconium aspiration syndrome, and excess weight gain than women with normal weight gain [9]. According to another study, the risk of premature birth and Cesarean section increases as the BMI increases $[10,11]$. Children of mothers with excess weight gain during pregnancy more commonly suffer from overweight and obesity in the future [10]. Research on animals provides valuable information on the mechanisms of fetal programming. It has been shown, i.e., that maternal obesity results in an increased expression of the placental fatty acid transporter, which is associated with an increased concentration of triglycerides in the fetus. Additionally, the activity of lipogenic genes increases, which results in an increased deposition of adipose tissue in the fetus [12]. On the other hand, too low weight gain in relation to the IOM standards entails the risk of a low birth weight in neonates delivered at term [9].

Nevertheless, according to Thangaratinam $S$ et al., about 20-40\% of pregnant women in Europe and the USA exhibit weight gain at variance with the recommendations [13].

The key requirements for optimum weight gain and the correct course of the pregnancy related to it, affecting the mother's and the child's health, seems to be a varied, balanced diet and physical activity [14, 15].

Further study is required to determine the influence of a programme of long-term physical activity through the second half of the pregnancy on the course of the pregnancy, the state of the neonate, the nutritional status of the mother, the method of delivery and the week of gestation at birth. There are numerous issues that need to be clarified beyond any doubt, especially in the face of often divergent results [14].

\section{OBJECTIVES}

The goal of this paper was to implement a properly planned, 18-week physical activity programme with pregnant women; and to continue it through the second and third trimesters to determine its influence on obstetric results (birth weight, method of delivery, week of gestation at birth, and weight gain in pregnancy) in patients with different durations of physical activity.

The period of a woman's pregnancy is a perfect moment to introduce the intervention as it motivates pregnant women to change their lifestyles to the potential benefit of the fetus.

\section{MATERIAL AND METHODS}

The study involved 71 pregnant women. All subjects were Caucasian patients of the Gynecology and Obstetrics Clinic of the Gynecology and Obstetrics Training Hospital, Poznań University of Medical Sciences. The study was conducted in 2014-2015 at the Institute of Dietetics, Department of Hygiene and Human Nutrition, Poznań University of Life Sciences; at the Gynaecology and Obstetrics Training Hospital, Poznań University of Medical Sciences; and at centres where pregnant women's physical activity is supported.

57 pregnant women completed the full course of the study. The causes of the reduction in the number of participants during the study were the hospitalisation of 2 women during the study that prevented their participation in consecutive stages and the unexplained withdrawal of 12 women.

The pregnant women in the study were divided into two groups. The median duration of their moderate physical activity (MPA) was used as the criterion for the division of the studied population. The median value was the borderline of the division between those women with shorter moderate physical activity (S_MPA group) and those with longer moderate physical activity (L_UAF group).

The examined groups of pregnant women were compared in terms of date of examination, age, weight, height and body mass index (BMI).

Information on such matters as age, weight before the pregnancy, and the week of pregnancy were collected from all the women during direct interviews prepared in cooperation with the medical doctor involved in the study, who was an obstetrics and gynecology specialist. The criteria for the women's inclusion in the study were an uncomplicated single pregnancy and no contraindications to physical activity during the pregnancy; while the exclusion criterion was hospitalisation during the study that prevented participation in its consecutive stages (Fig. 1).

All patients who qualified for the study were included in the physical activity programme (PAP). All the women took part in individual consultations with a dietician every 1 to 3 weeks from the date of qualification, to implement the principles of healthy nutrition during the pregnancy.

PAP was aimed to implement physical activity as recommended by the American Congress of Obstetricians and Gynaecologists (ACOG), i.e., 30 minutes of moderate physical activity every day or most days of the week. Participation in the programme was preconditioned by confirmation of no contraindications in this regard, given by the patient's prenatal care obstetrician. The exercise programme only included activities that are safe during pregnancy, i.e., pregnancy workouts, including yoga, swimming and stationary bicycle exercises. The activities were conducted under the supervision of qualified physiotherapists. Additionally, the 


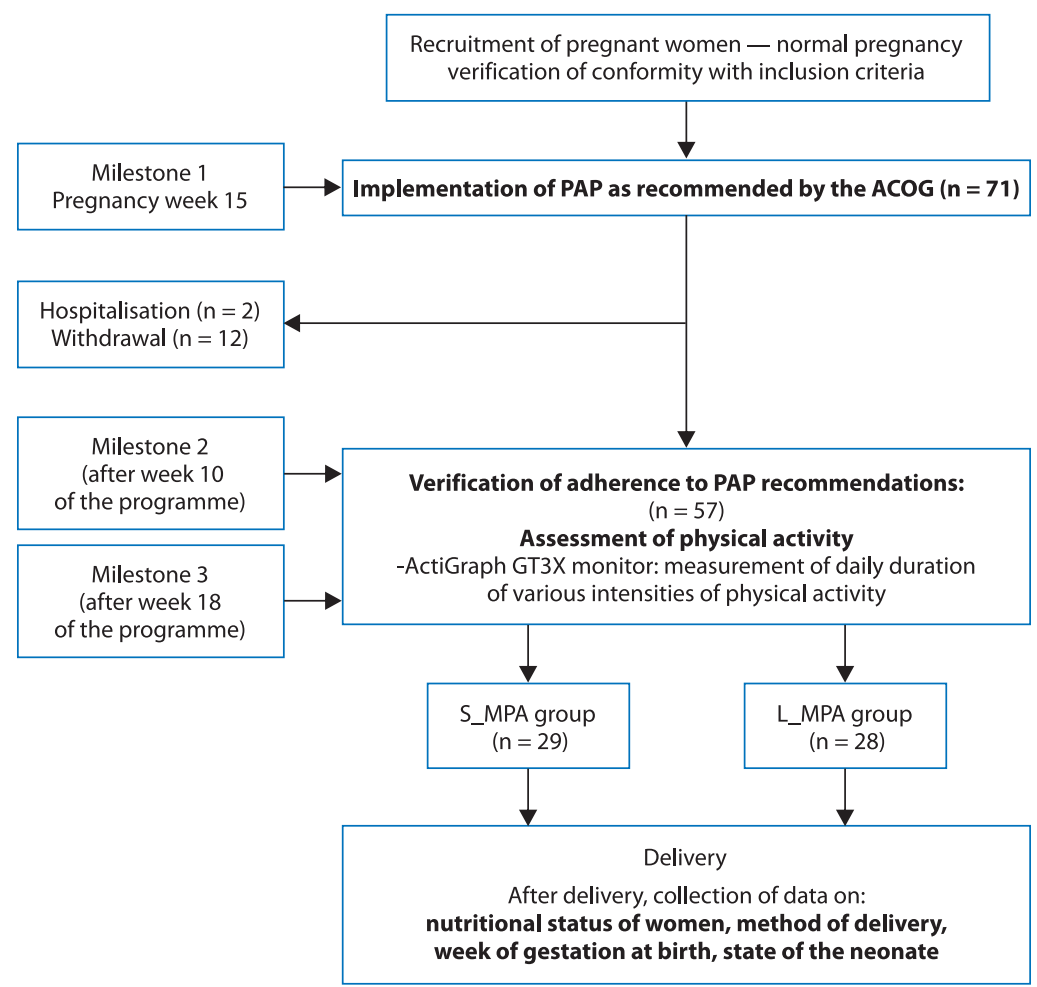

Figure 1. Flow chart of the study design

PAP — physical activity programme; MPA — moderate physical activity; S_MPA — group with shorter MPA; L_MPA — group with longer MPA

participating women were recommended to take part in the physical activities offered by their antenatal classes and were encouraged to take walks.

Moreover, every participant took part in a training session; and was advised on how to adjust the level of physical activity to their health status and past habits prior to their inclusion in the physical activity programme. The patients were informed about situations when they should limit their physical effort, in particular when the risks of miscarriage or premature labour can occur. They were also warned not to undertake any physical effort, or to immediately cease such efforts, if experiencing dizziness, headaches, chest pains, muscle weakness, pain or oedema in the calves, and/or other alarming signs. To encourage the pregnant women to take daily activity, at every meeting they were reminded of the benefits for mother and baby, of recreational physical activity. Additionally, each woman was encouraged to take a daily walk; and each received recommended special exercises to be done at home, from the Polish Association of Obstetricians [16].

10 and 18 weeks after the implementation of the programme, patient conformity with the recommended exercise regime was verified. The actual duration of each patient's physical activity across various intensity levels was measured and recorded with the ActiGraph GT3X monitor.
The accelerometric measurements were carried out by each pregnant woman twice over four consecutive days of the week. The participants wore the devices on a flexible belt around their waistline. The measurements were carried out during the subject's daily activities (excluding sleep and bathing).

The goal of the study was to assess the possible influence of PAP on birth weight (macrosomia and low birth weight), appropriate weight gain in the mother, the method of delivery and week of gestation at birth.

After delivery, data on the body weight of each pregnant woman on their day of delivery, the method of delivery, the week of gestation at birth, the birth weight and baby length was collected from maternity notes, the baby's medical record book and perinatal medical records.

Weight gain over the time of pregnancy was calculated from the body weight before the pregnancy and the body weight on the day of delivery. This data was evaluated in relation to the IOM 2009 [3] recommendations. Based on the birth weight, the occurrence of macrosomia (birth weight above $4000 \mathrm{~g}$ [17]) or low birth weights (weight below $2500 \mathrm{~g}$ ) was assessed $[18,19]$. The delivery methods were classified as vaginal delivery, Cesarean section, forceps delivery and vacuum extraction. At-term delivery was a delivery completed between the $38^{\text {th }}$ and $42^{\text {nd }}$ weeks of gestation; 


\begin{tabular}{|l|c|c|c|c|c|}
\hline \multicolumn{2}{|l|}{ Table 1. General profile of the study population } \\
\hline \multirow{2}{*}{ Parameter } & Mean & SD & Median & Min. & Max. \\
\hline Enrolment (week of gestation) & 15.9 & 4.97 & 15 & 8 & 23 \\
\hline Age upon enrolment (years) & 29.4 & 3.44 & 28 & 22 & 41 \\
\hline Body weight prior to pregnancy $[\mathrm{kg}]$ & 63 & 7.84 & 61 & 49 & 86.6 \\
\hline Body height $[\mathrm{m}]$ & 1.7 & 0.06 & 1.7 & 1.6 & 1.88 \\
\hline BMl prior to pregnancy $\left[\mathrm{kg} / \mathrm{m}^{2}\right]$ & 22 & 2.52 & 21.6 & 18.9 & 31.4 \\
\hline
\end{tabular}

SD - standard deviation

\begin{tabular}{|c|c|c|c|c|c|}
\hline Group in total $(n=57)$ & Mean & SD & Median & Min. & Max. \\
\hline UAF_milestone 2 & 28.38 & 18.42 & 25.00 & 0.25 & 89.25 \\
\hline UAF_milestone 3 & 19.10 & 14.28 & 17.75 & 0.25 & 81.75 \\
\hline UAF_mean of milestone 2 and 3 & 23.74 & 13.66 & 21.38 & 0.25 & 67.00 \\
\hline
\end{tabular}

UAF_2 - moderate physical activity in milestone 2 (after 10 weeks of the physical activity programme); UAF_3 - moderate physical activity at milestone 3 (after 18 weeks of the programme); UAF_mean - mean MPA for milestone 2 and 3; SD — standard deviation

and premature delivery was a delivery completed between weeks 23 and 37 [20].

\section{Statistics}

The results were analysed using the Statistica suite. Data from the questionnaires (count data) was analysed using chi-squared tests. When selecting the right test for quantitative results, two factors were taken into consideration: whether the data conformed to a normal distribution; and whether the variances of characteristics being compared were not significantly different. If these conditions were met, the Student's t-test was applied. Otherwise, the Mann-Whitney test was used. The relations between the characteristics being analysed was assessed with Pearson's correlation test. The statistically significant confidence interval for the analyses was set below $p=0.05$.

\section{Ethical approval}

All of the pregnant women were notified verbally and in writing prior to their enrolment about the detailed plan, assumptions and scope of the study; and each gave their written consent to participate in the study. The study project was approved by the Independent Ethics Committee at the Karol Marcinkowski University of Medical Sciences, Poznań (decision No. 248/10).

\section{RESULTS}

Table 1 presents the general characteristics of the study population. The women volunteered in pregnancy week $15.9 \pm 4.97$. The youngest patient of the group was 22 years old, and the oldest 41 years old. The average age of the patients at the day of their enrolment was $29.4 \pm 3.44$ (median: 28). The average pre-pregnancy body weight was $63 \pm 7.84$ (median: 61). The average BMI was within the normal range and amounted to $22 \pm 2.52 \mathrm{~kg} / \mathrm{m}^{2}$ (median: 21.6); the maximum BMI was 31.4; and the minimum BMI was $18.9 \mathrm{~kg} / \mathrm{m}^{2}$.

Table 2 presents the results of measuring the duration of daily moderate physical activity for all the pregnant women with the monitor at milestone 2 (after 10 weeks of intervention) and milestone 3 (after 18 weeks of intervention). Only moderately-intense physical activity was taken into consideration as it was the only intensity where the study's parameters could be differentiated, given that virtually no high-intensity or very high-intensity physical activity occurred. At both the milestones after 10 weeks and 18 weeks of the PAP there were differences in the duration of physical activity, therefore the women were divided into two groups. The division criterion was the median of the duration of moderate physical activity (MPA) calculated at each milestone and the mean median from the two milestones (Tab. 2). The value of the median was, therefore, the dividing line between the women with shorter-duration moderate physical activity (group S_MPA) and those with longer-duration moderate physical activity (group L_MPA) (Tab. 3).

This division significantly differentiated the subgroups with regards to the duration of physical activity. It was found that at both the milestones after 10 weeks and 18 weeks, the mean values of the results for the longer-duration activity group were about three times greater than the parallel 
Table 3. The results of the measurements of the daily MPA, after 10 and after 18 weeks of the intervention, broken down by group of shorter duration (group S_MPA) and longer duration physical activity (group L_MPA) MPA, separated from the total group

\begin{tabular}{|l|l|c|c|c|c|c|c|}
\hline & $\mathbf{n}$ & Boundary (median) & Mean & SD & Min. & Max. \\
\hline MPA_2_L_MPA & 31 & & 41.19 & 15.07 & 25 & 89.25 \\
\hline MPA_2_S_MPA & 26 & 25.00 & 13.12 & 6.43 & 0.25 & 24.25 \\
\hline MPA_3_L_MPA & 29 & & 29.10 & 13.09 & 17.75 & 81.75 \\
\hline MPA_3_S_MPA & 28 & 17.75 & 8.73 & 5.10 & 0.25 & 17.5 \\
\hline MPA_mean_L_MPA & 28 & & 34.26 & 11.38 & 21.5 & 6.001 \\
\hline MPA_mean_S_MPA & 29 & 21.38 & 13.58 & 5.54 & 0.25 & 21.375 \\
\hline
\end{tabular}

*Mann-Whitney test

SD — standard deviation; MPA — moderate physical activity; S_MPA — group with shorter MPA; L_MPA — group with longer MPA

Table 4. The general profile of the population broken down by groups of shorter (S_MPA) and longer moderate physical activity (L_MPA)

\begin{tabular}{|c|c|c|c|c|c|c|c|}
\hline & \multicolumn{3}{|c|}{ S_MPA $(n=29)$} & \multicolumn{3}{|c|}{ L_MPA $(n=28)$} & \multirow{2}{*}{$\mathbf{p}^{*}$} \\
\hline & $\mathrm{x} \pm \mathrm{SD}$ & Median & Min-Max & $\mathrm{x} \pm \mathrm{SD}$ & Median & Min-Max & \\
\hline Age upon enrolment [years] & $29.7 \pm 3.90$ & 28 & $22-41$ & $29.04 \pm 2.92$ & 28 & $24-37$ & 0.643 \\
\hline Enrolment (week of gestation) & $16.1 \pm 5.15$ & 16 & $8-23$ & $15.68 \pm 4.85$ & 13 & $9-23$ & 0.678 \\
\hline Body height [cm] & $169 \pm 6.53$ & 168 & $160-184$ & $168.93 \pm 5.3$ & 169 & $159-180$ & 0.342 \\
\hline Body weight prior to pregnancy [kg] & $62.6 \pm 9.07$ & 60 & $49.0-86.6$ & $63.38 \pm 6.47$ & 63 & $55-79$ & 0.367 \\
\hline BMI prior to pregnancy $\left[\mathrm{kg} / \mathrm{m}^{\wedge} 2\right]$ & $21.7 \pm 2.70$ & 21.27 & $18.8-31.4$ & $22.24 \pm 2.37$ & 22.16 & $19.3-28$ & 0.621 \\
\hline
\end{tabular}

*Mann-Whitney test; key in Table 3

results in the shorter-duration activity group; therefore, a mean median from both milestones was used in subsequent analyses (21.38). Accordingly, the duration of physical activity in the group that exercised for shorter periods was below 21.38, and in the group that exercised longer, it was above 21.38 minutes (Tab. 3).

Table 4 presents the profile of pregnant subjects divided into the groups with shorter S_MPA $(n=29)$ and longer L_MPA (n-28) physical activity. The age of the patients in the groups was not significantly different ( $29.7 \pm 3.90$ vs. $29.0 \pm 2.92)$; neither was height and body weight before pregnancy $(62.6 \pm 9.07$ vs. $63.4 \pm 6.47)$; nor was and BMI, which was in the normal range for both groups $(21.9 \pm 2.70$ vs. $22.2 \pm 2.37)$. The week of gestation that the patients volunteered for the study was also comparable ( $16.1 \pm 5.15$ vs. $15.7 \pm 4.85)$.

According to Table 5, the mean gestational age was within the norm for both groups ( $40.1 \pm 1.43$ vs. $39.3 \pm 2.12$ gestation week).

No significant difference in terms of birth weight was found in the groups. The mean birth weight was within the norm for both groups and amounted to $3528.3 \pm 424.95 \mathrm{~g}$ in group S_MPA and $3281.6 \pm 632.26 \mathrm{~g}$ in group L_MPA. The body length of the neonates in groups S_MPA and L_MPA were $54.9 \pm 1.84 \mathrm{~cm}$ and $54.25 \pm 3.61 \mathrm{~cm}$ respectively. Further differences between the parameters were not statistically significant. Furthermore, the 5-minute Apgar score did not differentiate the study groups significantly

\begin{tabular}{|c|c|c|c|}
\hline & S_MPA $(n=29)$ & L_MPA $(n=28)$ & p* \\
\hline $\begin{array}{l}\text { Week of } \\
\text { gestation } \\
\text { at birth }\end{array}$ & $\begin{array}{c}40.1 \pm 1.43 \\
(37-43)\end{array}$ & $\begin{array}{c}39.3 \pm 2.12 \\
(34-42)\end{array}$ & 0.1190 \\
\hline
\end{tabular}

*Mann-Whitney test; key in Table 3

either: $9.97 \pm 0.19$ (interval 9-10) in group S_MPA and $9.89 \pm 0.42$ (interval 8-10) in group L_MPA (Tab. 6).

After data had been collected following birth, an attempt was made to verify whether there was a relationship between the duration of the MPA and the above-mentioned obstetric results. It was observed that when comparing the group with the longer-duration activity and the group with shorter-duration physical activity, in the latter, there were six times more women who showed weight gain in excess of the norm (EG) (7.14 vs. $41.38 \%)$. This result was a significant differentiating factor. $30 \%$ fewer women exhibited weight gain value within the norm ( $\mathrm{N}$ ) (71.43 vs. 44.83\%). At the same time, in group L_MPA, $8 \%$ more women than in group S_MPA exhibited too-low a weight gain (TL) (21.43 vs. 13.79\%) (Tab. 7). Comparable numbers of patients in both groups gave vaginal births (75.00 vs. $72.41 \%$ ). Moreover, the percentage of Caesarean sections did not differentiate the groups (21.43 vs. 20.69\%). In group S_MPA, however, two cases of vacuum extraction (VE) were noted, which did not occur 


\begin{tabular}{|c|c|c|c|c|c|c|c|}
\hline & \multicolumn{3}{|c|}{ S_MPA $(n=29)$} & \multicolumn{3}{|c|}{ L_MPA $(n=28)$} & \multirow{2}{*}{$\mathbf{p}^{*}$} \\
\hline & $\mathrm{x} \pm \mathrm{SD}$ & Median & Min-Max & $\mathrm{x} \pm \mathrm{SD}$ & Median & Min-Max & \\
\hline Birth weight [g] & $3528.3 \pm 424.95$ & 3490 & $2400-4400$ & $3281.6 \pm 632.3$ & 3430 & $1470-4350$ & 0.185 \\
\hline Birth length $[\mathrm{cm}]$ & $54.9 \pm 1.84$ & 55 & $51-58$ & $54.25 \pm 3.61$ & 55 & $45-59$ & 0.917 \\
\hline APGAR score & $9.97 \pm 0.19$ & 10 & $9-10$ & $9.89 \pm 0.42$ & 10 & $8-10$ & 0.536 \\
\hline
\end{tabular}

*Mann-Whitney test; key in Table 3

Table 7. Relationship between the duration of the MPA and weight gain in pregnant women

\begin{tabular}{|c|c|c|c|c|c|}
\hline \multirow{2}{*}{\multicolumn{2}{|c|}{ Pearson's chi-squared: $9.01294, p=.0110$}} & \multicolumn{4}{|c|}{ weight gain in women* } \\
\hline & & \multirow{2}{*}{$\begin{array}{c}\text { TS } \\
4\end{array}$} & \multirow{2}{*}{$\begin{array}{l}\mathbf{N} \\
13\end{array}$} & \multirow{2}{*}{$\begin{array}{c}\text { EG } \\
12\end{array}$} & \multirow{2}{*}{$\begin{array}{c}\text { Total } \\
29\end{array}$} \\
\hline Number & \multirow{3}{*}{ S_MPA } & & & & \\
\hline$\%$ of row & & 13.79 & 44.83 & 41.38 & \\
\hline$\%$ of all & & 7.02 & 22.81 & 21.05 & 50.88 \\
\hline Number & \multirow{3}{*}{ L_MPA } & 6 & 20 & 2 & 28 \\
\hline$\%$ of row & & 21.43 & 71.43 & 7.14 & \\
\hline$\%$ of all & & 10.53 & 35.09 & 3.51 & 49.12 \\
\hline Number & \multirow{2}{*}{ Total } & 10 & 33 & 14 & 57 \\
\hline$\%$ of all & & 17.54 & 57.89 & 24.56 & \\
\hline
\end{tabular}

Key in Table 3

*EG - gain in excess of the norm; $\mathrm{N}$ - normal; TS - too small

\begin{tabular}{|c|c|c|c|c|c|c|}
\hline \multirow{2}{*}{\multicolumn{2}{|c|}{ Pearson's chi-squared: $2.98337, p=.394$}} & \multicolumn{5}{|c|}{ method of delivery* } \\
\hline & & \multirow{2}{*}{$\begin{array}{l}\text { VB } \\
21\end{array}$} & \multirow{2}{*}{$\frac{\text { CC }}{6}$} & \multirow{2}{*}{$\begin{array}{c}\text { VE } \\
2\end{array}$} & \multirow{2}{*}{$\begin{array}{c}\text { FD } \\
0\end{array}$} & \multirow{2}{*}{$\begin{array}{c}\text { Total } \\
29\end{array}$} \\
\hline Number & \multirow{3}{*}{ S_MPA } & & & & & \\
\hline$\%$ of row & & 72.41 & 20.69 & 6.89 & 0 & \\
\hline$\%$ of all & & 36.84 & 10.53 & 3.509 & 0 & 50.88 \\
\hline Number & \multirow{3}{*}{ L_MPA } & 21 & 6 & 0 & 1 & 28 \\
\hline$\%$ of row & & 75.00 & 21.43 & 0 & 3.57 & \\
\hline$\%$ of all & & 36.84 & 10.53 & 0 & 1.75 & 49.12 \\
\hline Number & \multirow{2}{*}{ Total } & 42 & 12 & 2 & 1 & 57 \\
\hline$\%$ of all & & 73.68 & 21.05 & 3.509 & 1.75 & \\
\hline
\end{tabular}

Key in Table 3

${ }^{*} \mathrm{CC}$ - Caesarean section; $\mathrm{VB}$ - vaginal birth; FD — forceps delivery; VE — vacuum extraction

in the group that exercised longer (6.89 vs. 0\%) (Tab. 8); and twice as many cases of macrosomia occurred in group S_MPA compared with group L_MPA (13.79vs.7.14\%) (Tab.9). Three cases of premature births $(10.71 \%)$ were noted in the group that exercised longer with none occurring in the other group (Table 10). Additionally, three times as many cases of low birth weight (10.71 vs. $3.45 \%$ ) were found in the former group as compared to the latter (Tab. 9). No statistically significant dependencies were found in regard to low birth weight (Tab. 9, 10). Most pregnant women in both groups delivered at term ( 89.29 vs. $100 \%)$. The groups were not significantly different in terms of gestation at birth (Tab. 10).

\section{DISCUSSION}

Most of the studies conducted to date have focused on the results of short-term exercise programmes. Some studies encouraged pregnant women to take up physical activity (such as walks and workouts), but the actual activity was not monitored [21]. 
Table 9. The relationship between the duration of the MPA and the occurrence of macrosomia and LBW

\begin{tabular}{|c|c|c|c|c|c|}
\hline \multirow{2}{*}{\multicolumn{2}{|c|}{ Pearson's chi-squared: $1.67091, p=.433676$}} & \multicolumn{4}{|c|}{ Birth weight } \\
\hline & & \multirow{2}{*}{$\begin{array}{c}\text { Normal } \\
24\end{array}$} & \multirow{2}{*}{$\begin{array}{c}\text { Low birth weight } \\
1\end{array}$} & \multirow{2}{*}{$\begin{array}{c}\text { Macrosomia } \\
4\end{array}$} & \multirow{2}{*}{$\begin{array}{c}\text { Total } \\
29\end{array}$} \\
\hline Number & \multirow{3}{*}{ S_MPA } & & & & \\
\hline$\%$ of row & & 82.76 & 3.45 & 13.79 & \\
\hline$\%$ of all & & 42.11 & 1.75 & 7.02 & 50.88 \\
\hline Number & \multirow{3}{*}{ L_MPA } & 23 & 3 & 2 & 28 \\
\hline$\%$ of row & & 82.14 & 10.71 & 7.14 & \\
\hline$\%$ of all & & 40.35 & 5.26 & 3.51 & 49.12 \\
\hline Number & \multirow{2}{*}{ Total } & 47 & 4 & 6 & 57 \\
\hline$\%$ of all & & 82.46 & 7.02 & 10.53 & \\
\hline
\end{tabular}

Key in Table 3

Table 10. The relationship between the duration of the MPA and the gestation age at birth (premature birth and birth at term)

\begin{tabular}{|c|c|c|c|c|}
\hline \multirow{2}{*}{\multicolumn{2}{|c|}{$\begin{array}{l}\text { Pearson's chi-squared: } 3.27976, d f=1 \text {, } \\
p=.070139\end{array}$}} & \multicolumn{3}{|c|}{ Gestation age at birth } \\
\hline & & \multirow{2}{*}{$\begin{array}{c}\text { At term } \\
29\end{array}$} & \multirow{2}{*}{$\begin{array}{c}\text { Premature } \\
0\end{array}$} & \multirow{2}{*}{$\begin{array}{c}\text { Total } \\
29\end{array}$} \\
\hline Number & \multirow{3}{*}{ S_MPA } & & & \\
\hline$\%$ of row & & 100 & 0 & \\
\hline$\%$ of all & & 50.88 & 0 & 50.88 \\
\hline Number & \multirow{3}{*}{ L_MPA } & 25 & 3 & 28 \\
\hline$\%$ of row & & 89.29 & 10.71 & \\
\hline$\%$ of all & & 43.86 & 5.26 & 49.12 \\
\hline Number & \multirow{2}{*}{ Total } & 54 & 3 & 57 \\
\hline$\%$ of all & & 94.74 & 5.26 & \\
\hline
\end{tabular}

Key in Table 3

According to Leite CF et al., some studies, of both mothers and children, have produced contradictory results, owing to the lack of any significant relationship between the physical activity and the clinical results; with the result that what was observed was'the lack of their [PA] influence' rather than 'negative impacts' of PA. Leite CF et al. believe that contradictory results may also be related to the fact that most studies to date analysed the outcomes of short-term exercise programmes with small groups of patients [22].

The results of this study, on the other hand, demonstrate that it is possible to implement and monitor a long-term physical activity programme in pregnant women (in line with ACOG requirements), that continues through the second half of the pregnancy and that affects perinatal outcomes.

The authors compared obstetric results in two groups of pregnant women who exercised, respectively, for more and less than 21 minutes a day. The programme was implemented in the second and third trimesters for 18 weeks. It should be noted that both groups were homogeneous in terms of age, body weight, BMI and ethnic group.

Participation in daily physical activity at various levels of intensity was measured, along with the duration of the activity, by monitoring the pregnant women's activities with a triaxial accelerometer; which is definitely a strength of our study. There are, however, some limitations.

Unfortunately, the relatively long duration of the study probably had an impact on the fact that the target group was a smaller population than the authors of the work expected, because $20 \%$ of women withdrew from the study or needed hospitalization during the programme. Similar problems are also described in other studies involving pregnant women $[5,23]$. The consequence of a small number of participants could be the inability to establish significant relationships between the duration of physical activity and pregnancy results (the occurrence of macrosomia, low body weight, gestation age at birth and delivery method) or different results from other authors.

Most literature data on the physical activity undertaken by women during pregnancy does not include reports of any adverse influence on the state of the fetus or on premature births [24-27]. According to the results of a meta-analysis of randomised studies and cohort studies, there is an inverse relationship between physical activity during pregnancy and the occurrence of macrosomia. In groups of physically 
active patients, a lower risk of premature birth is observed $[23,15]$

In the study population, it was not possible to show a statistically significant relationship between the duration of physical activity and the occurrence of macrosomia and pre-term delivery. In the S_MPA group, however, there were twice as many cases of macrosomia. At the same time, in the L_MPA group, three cases of premature delivery were noted, unlike in the group that exercised for shorter periods. In the L_MPA group, 8\% more mothers than in the second study group exhibited weight gain below the norm.

The number of vaginal births was comparable in women who exercised for shorter periods, however it was in this group that two cases of vacuum extraction occurred; while none occurred in the group that exercised more.

The type of activity the pregnant women took part in could also have had a beneficial influence on the results as the largest share of women in both groups participated in workout and yoga dedicated to pregnant women. According to Kozłowska and Stanek as well as Kosinska, participation in such classes improves the functional capacity of neonates and the active participation of the women in labour [28-30].

The results may indicate a statistically variable relationship between weight gain and the duration of moderate-intensity physical activity, as it was only intensity levels that could differentiate the parameters studied in circumstances where virtually no high-intensity and very high-intensity physical activity was recorded. It was found that significantly more women with weight gains within the recommended range exercised for at least 21 minutes a day in the second half of pregnancy. There were six times more women in the S_MPA group with excessive weight gain (significantly different results); and normal weight gain was recorded in almost 30\% fewer patients in this group.

Recent meta-analysis including only randomized controlled trials also indicates a positive effect of physical activity programs in preventing excessive weight gain during pregnancy $[23,5]$. Silva et al. argue that a group of women exercising during the second and third trimester of pregnancy had a weight gain lower by $1 \mathrm{~kg}$ than the group that did not undertake any physical activity. Unfortunately, no statistically significant dependencies were found in this regard [5].

\section{CONCLUSIONS}

The results show that exercise in the second half of pregnancy may be beneficial to the mother by contributing to an appropriate weight gain during pregnancy. It should be noted that the positive influence of physical activity was found to occur in patients who exercised at least 21 minutes a day.
Another point of great importance is that the knowledge about lifestyle change gained by participants in the programme may contribute to obesity control not only in mothers but also in their children because, according to epidemiological data, excessive weight gain in pregnancy increases the risk of obesity in the child.

The influence of a long-term physical activity programme on the course and outcomes of pregnancy calls for further observation in studies with larger populations.

\section{REFERENCES}

1. Position of the American Dietetic Association: Nutrition and Lifestyle for a Healthy Pregnancy Outcome. Journal of the American Dietetic Association. 2008; 108(3): 553-561, doi: 10.1016/j.jada.2008.01.030.

2. Muktabhant $B$, Lumbiganon $P$, Ngamjarus $C$, et al. Interventions for preventing excessive weight gain during pregnancy. Cochrane Database Syst Rev. 2012(4): CD007145, doi: 10.1002/14651858.CD007145.pub2, indexed in Pubmed: 22513947.

3. Determining Optimal Weight Gain. Weight gain during pregnancy. Reexaming the guidelines. National Academies Press, Washington, DC 2009.

4. Streuling I, Beyerlein A, von Kries R. Can gestational weight gain be modified by increasing physical activity and diet counseling? A meta-analysis of interventional trials. Am J Clin Nutr. 2010; 92(4): 678-687, doi: 10.3945/ajcn.2010.29363, indexed in Pubmed: 20668049.

5. da Silva SG, Hallal PC, Domingues MR, et al. A randomized controlled trial of exercise during pregnancy on maternal and neonatal outcomes: results from the PAMELA study. Int J Behav Nutr Phys Act. 2017; 14(1): 175, doi: 10.1186/s12966-017-0632-6, indexed in Pubmed: 29273044.

6. Ramachenderan J, Bradford J, McLean M. Maternal obesity and pregnancy complications: a review. Aust N Z J Obstet Gynaecol. 2008; 48(3): 228-235, doi: 10.1111/j.1479-828X.2008.00860.x, indexed in Pubmed: 18532950.

7. Bogaerts A, Ameye L, Bijlholt M, et al. INTER-ACT: prevention of pregnancy complications through an e-health driven interpregnancy lifestyle intervention - study protocol of a multicentre randomised controlled trial. BMC Pregnancy Childbirth. 2017; 17(1): 154, doi: 10.1186/s12884017-1336-2, indexed in Pubmed: 28549455.

8. Siega-Riz AM, Siega-Riz AM, Laraia B. The implications of maternal overweight and obesity on the course of pregnancy and birth outcomes. Matern Child Health J. 2006; 10(5 Suppl): S153-S156, doi: 10.1007/s10995-006-0115-X, indexed in Pubmed: 16927160.

9. Stotland NE, Cheng YW, Hopkins LM, et al. Gestational weight gain and adverse neonatal outcome among term infants. Obstet Gynecol. 2006; 108(3 Pt 1): 635-643, doi: 10.1097/01.AOG.0000228960.16678. bd, indexed in Pubmed: 16946225.

10. Kominiarek MA, Peaceman AM. Gestational weight gain. Am J Obstet Gynecol. 2017; 217(6):642-651, doi: 10.1016/j.ajog.2017.05.040, indexed in Pubmed: 28549978.

11. Briese $V$, Voigt $M$, Hermanussen $M$, et al. Morbid obesity: pregnancy risks, birth risks and status of the newborn. Homo. 2010; 61(1): 64-72, doi: 10.1016/j.jchb.2009.11.002, indexed in Pubmed: 20042187.

12. Alfaradhi MZ, Ozanne SE. Developmental programming in response to maternal overnutrition. Front Genet. 2011; 2: 27, doi: 10.3389/fgene.2011.00027, indexed in Pubmed: 22303323.

13. Thangaratinam $S$, Jolly K. Obesity in pregnancy: a review of reviews on the effectiveness of interventions. BJOG. 2010; 117(11): 1309-1312, doi: 10.1111/j.1471-0528.2010.02670.x, indexed in Pubmed: 20862792.

14. Thangaratinam S, Rogozinska $E$, Jolly $K$, et al. Effects of interventions in pregnancy on maternal weight and obstetric outcomes: meta-analysis of randomised evidence. BMJ. 2012; 344: e2088, doi: 10.1136/bmj.e2088, indexed in Pubmed: 22596383.

15. Barakat $\mathrm{R}$, Pelaez $\mathrm{M}$, Cordero $\mathrm{Y}$, et al. Exercise during pregnancy protects against hypertension and macrosomia: randomized clinical trial. American Journal of Obstetrics and Gynecology. 2016; 214(5): 649.e1-649. e8, doi: 10.1016/j.ajog.2015.11.039.

16. Bień AM. Opieka nad kobietą ciężarną. Warszawa: Wydawnictwo Lekarskie PZWL. ; 2009.

17. Dłużniewski M, Grzywanowska-Łaniewska I, Wielgś M. Ciąża. Problemy internisty i kardiologa. Lublin: Wydawnictw Czelej Sp. z . z o o. ; 2012. 
18. World Health Organisation. Public health aspects of low birth weight. Third report of the Expert Committee on Maternal and Child Health. WHO Tech Report Serv. 1961; 217: 13.

19. Nobile CGA, Raffaele G, Altomare C, et al. Influence of maternal and social factors as predictors of low birth weight in Italy. BMC Public Health. 2007; 7: 192, doi: 10.1186/1471-2458-7-192, indexed in Pubmed: 17683559.

20. World Health Organisation. The prevention of perinatal mortality and morbidity. WHO Tech Report Serv. ; 1970: 457.

21. Polley BA, Wing RR, Sims CJ. Randomized controlled trial to prevent excessive weight gain in pregnant women. Int J Obes Relat Metab Disord. 2002; 26(11): 1494-1502, doi: 10.1038/sj.ijo.0802130, indexed in Pubmed: 12439652.

22. Leite CF, do Nascimento SL, Helmo FR, et al. An overview of maternal and fetal short and long-term impact of physical activity during pregnancy. Arch Gynecol Obstet. 2017; 295(2): 273-283, doi: 10.1007/s00404-0164204-9, indexed in Pubmed: 27761731.

23. da Silva SG, Ricardo LI, Evenson KR, et al. Leisure-Time Physical Activity in Pregnancy and Maternal-Child Health: A Systematic Review and Meta-Analysis of Randomized Controlled Trials and Cohort Studies. Sports
Med. 2017; 47(2): 295-317, doi: 10.1007/s40279-016-0565-2, indexed in Pubmed: 27282925.

24. Wang TW, Apgar BS. Exercise during pregnancy. Am Fam Physician. 1998; 57(8): 1846-52, 1857, indexed in Pubmed: 9575323.

25. Brown W. The benefits of physical activity during pregnancy. J Sci Med Sport. 2002; 5(1): 37-45, doi: 10.1016/s1440-2440(02)80296-1.

26. Clapp JF. Exercise during pregnancy. A clinical update. Clin Sports Med. 2000; 19(2): 273-286, doi: 10.1016/s0278-5919(05)70203-9, indexed in Pubmed: 10740759.

27. Penney DS. The effect of vigorous exercise during pregnancy. J Midwifery Womens Health. 2008; 53(2): 155-159, doi: 10.1016/j.jmwh.2007.12.003, indexed in Pubmed: 18308267.

28. Kozłowska J, Stanek M. Przebieg porodu i połogu u kobiet po kinezystumulacji w „szkole rodzenia"-próba oceny. Ginekol Pol. 2002; 5: 439-43.

29. Kosińska K, Krychowska A, Wielgoś M, et al. Postawy ciężarnych wobec porodu-analiza form przygotowania i preferencji. Ginekol Pol. 2005; 76: 973-8.

30. Babbar S, Parks-Savage AC, Chauhan SP. Yoga during pregnancy: a review. Am J Perinatol. 2012; 29(6): 459-464, doi: 10.1055/s-0032-1304828, indexed in Pubmed: 22399208. 